DR. ADAM CERISE (Orcid ID : 0000-0002-9605-2053)

DR. JONATHAN A FRIDELL (Orcid ID : 0000-0002-8708-1506)

Article type : Review Article

Pancreas transplantation would be easy if the recipients were not diabetic: A practical guide to postoperative management of diabetic complications in pancreas transplant recipients.

\title{
Adam Cerise
}

Jeanne M. Chen

John A. Powelson

Andrew J. Lutz

Jonathan A. Fridell

Department of Surgery, Division of Abdominal Transplant Surgery, Indiana University School of Medicine

Jonathan A. Fridell, MD, FACS

This is the author's manuscript of the article published in final edited form as:

Cerise, A., Chen, J. M., Powelson, J. A., Lutz, A. J., \& Fridell, J. A. (2021). Pancreas transplantation would be easy if the recipients were not diabetic: A practical guide to post-operative management of diabetic complications in pancreas transplant recipients. Clinical Transplantation, 35(5), e14270. https://doi.org/10.1111/ctr.14270 


\section{Professor of Surgery}

Chief of Abdominal Transplant Surgery

Director of Pancreas Transplantation

Indiana University School of Medicine

550 N University BLVD, Room 4601

Indianapolis, IN 46202

Email: jfridell@iupui.edu

T: 317-944-4370

F: 317-968-1254

Diabetes mellitus DM

Enhanced Recovery After Surgery ERAS

nasogastric NG

pancreas after kidney PAK

pancreas transplant alone PTA

simultaneous pancreas-kidney SPK

Type 1 Diabetes Mellitus T1DM

Acknowledgement: The title of this manuscript was a direct quote from our mentor and teacher, Dr.

Mark Pescovitz, who sadly passed away in 2010

Data sharing is not applicable to this article as no new data were created or analyzed in this study.

This article is protected by copyright. All rights reserved 


\begin{abstract}
Diabetes mellitus remains a major public health problem throughout the United States with over $\$ 300$ billion spent in total cost of care annually. In addition to being a leading cost of kidney failure, diabetes causes a host of secondary hyperglycemic-related complications including gastroparesis and orthostatic hypotension. While pancreas transplantation has been established as an effective treatment for diabetes, providing long-term normoglycemia in recipients, the secondary complications of diabetes mellitus persist complicating the post-operative course of an otherwise successful pancreas transplantation. This review describes the mechanism and impact of diabetic gastroparesis and orthostatic hypotension in the post-operative course of pancreas transplant patients and analyzes the various treatment modalities, based on current data and extensive experience at our institution, to treat these respective complications. While gastroparesis and orthostatic hypotension remain challenging post-operative conditions, the establishment of institutional protocols and step-up treatment algorithms can help define more effective therapies.
\end{abstract}

\title{
Introduction
}

Diabetes mellitus (DM) has long been established as a major public health problem throughout the United States and the world, as well as a leading cause of kidney failure, new onset blindness, and non-traumatic lower limb amputations. ${ }^{1}$ In addition, diabetes causes a host of secondary complications in those it afflicts including gastroparesis, autonomic neuropathy (ie hypoglycemia unawareness and orthostatic hypotension), peripheral neuropathy, retinopathy, peripheral vascular disease, cardiac disease, and depression. In the United States alone, the total cost of diabetes care was a staggering $\$ 327$ billion in $2017 .^{2}$ The Diabetes Control and Complications Trial established tight glycemic control as the only effective modality to avoid the development of secondary complications. ${ }^{3}$ Pancreas transplantation, first performed simultaneously with a kidney transplant at the University of Minnesota by Lillehei and Kelly in 1966, has become a wellestablished treatment modality for patients primarily with Type 1 Diabetes Mellitus (T1DM) since the 1980 s with ever improving outcomes. ${ }^{4,5}$ The American Diabetes Association has advocated pancreas transplantation in diabetic patients with end stage diabetic nephropathy who have 
undergone or are planning to undergo kidney transplantation, brittle diabetes with hypoglycemia unawareness, frequent severe metabolic complications (ie,, ketoacidosis), clinical inability to undergo exogenous insulin therapy, and failure of exogenous insulin therapy to prevent the metabolic complications of diabetes mellitus. ${ }^{6}$ Despite excellent overall survival (>90\%) for simultaneous pancreas-kidney (SPK), pancreas after kidney (PAK), and pancreas transplant alone (PTA) at 5 years and much improved graft survival (73\%, 64\%, and 53\% for SPK, PAK, and PTA respectively at 5 years), the number of pancreas transplants performed continues to decline yearly in the United States. ${ }^{1,7}$ Despite establishment of euglycemia, many of these secondary complications of diabetes may persist and can certainly complicate the post-operative course following successful pancreas transplantation. Gastroparesis and autonomic neuropathy (specifically orthostatic hypotension) in particular have a propensity to specifically cause difficulties during the early and late post-operative course of these patients, leading to increased readmissions, medical cost, and morbidity secondary to further procedures.

This review describes the impact of gastroparesis and autonomic neuropathy on the postoperative course of pancreas transplant patients and analyzes the various treatment modalities, based on current evidence, to treat these respective complications and mitigate their effect on pancreas transplant patients.

\section{Gastroparesis and gastrointestinal dysmotility: Incidence, Impact, and Implications}

Gastroparesis has an estimated prevalence of 40\% in T1DM patients presenting to tertiary care centers and $5 \%$ in the T1DM general population..$^{8,9}$ The etiology of diabetic gastroparesis is thought to be related to reduced insulin and insulin-like growth factor 1 signaling due to acute and chronic hyperglycemia causing damage to the interstitial cells of Cajal and enteric neurons of the stomach. ${ }^{10,11}$ This damage results in poor fundic relaxation, ineffective corpus-antral contractions, and failure of pyloric relaxation. ${ }^{10-14}$ The cumulative effect of these abnormalities results in the symptoms of early satiety, prolonged fullness, nausea, and vomiting. ${ }^{15}$ Furthermore, the unpredictability in gastric emptying can cause erratic post-prandial glucose levels that combined

This article is protected by copyright. All rights reserved 
with improper timing of insulin boluses can produce severe episodes of hypoglycemia and hyperglycemia, even with ketoacidosis, in diabetic patients. To further complicate matters, patients with chronic renal dysfunction and subsequent uremia experience gastric dysfunction that is exacerbated by hemodialysis. ${ }^{16,17}$ Diabetic patients have been shown to have increased rates of both small and large bowel motility disorders; and despite normal pre-operative gastric emptying studies, it is our experience that all pancreas transplant patients remain at risk for issues with exacerbation of post-operative motility disorders.

Prior studies examining post-transplant gastric emptying in SPK patients via electrogastrogram (EGG) and quality of life surveys, noted improvements both in EGG normalization and a reduction in perception of delayed gastric emptying (DGE) symptoms. ${ }^{19-21}$ However, a followup study on 42 SPK patients by Cashion et al noted persistence of abnormal EGGs in $31 \%$ of patients 2 years after transplant. ${ }^{22}$ Furthermore, data from our own institution examining 526 pancreas transplant patients from 2003-2014 noted symptomatic post-transplant gastroparesis present in $18 \%$ of all patients. ${ }^{23}$ This rate remained consistent despite type of pancreas transplantation, whether SPK, PAK, or PTA, with rates of $17 \%, 22 \%$, and $18 \%$, respectively. Although gastroparesis was not associated with inferior survival outcomes in this large population of pancreas transplant patients, it was associated with a mildly longer length of initial stay and an almost $30 \%$ increase in hospital readmission for nausea and emesis over the first 3 months following transplant.

This article is protected by copyright. All rights reserved 


\section{Treatment: Preemptive Strategies}

The approach to managing gastroparesis following pancreas transplantation starts with the assumption that all patients with diabetes undergoing major abdominal surgery are at risk for motility issues, gastroparesis exacerbation and prolonged ileus. Early goals are to minimize medications that may exacerbate this, particularly narcotics, regain bowel function, and initiate oral

intake as early as possible (Figure 1). Furthermore, maintenance immunosuppression protocols that include medications with known gastrointestinal side effects such as mycophenolate mofetil or mycophenolic acid may also exacerbate or mimic these symptoms further confusing the picture. In fact, in order to avoid or minimize the impact of these medications in the diabetic recipient population, we have switched to a tacrolimus/sirolimus based maintenance immunosuppression for all pancreas transplant recipients with the addition of a reduced dosage of mycophenolate mofetil for pancreas transplant alone recipients. ${ }^{24}$ Early PO intake and abandonment of post-operative nasogastric tube (NG) decompression has largely been adopted by other surgical specialties in an effort to stimulate earlier return of bowel function, as well as decrease hospital costs and postoperative complication rates. Colorectal surgery has adopted a set of Enhanced Recovery After Surgery (ERAS) guidelines that include both early PO intake and use of NG decompression only in the setting of post-op ileus. ${ }^{25} \mathrm{~A}$ study in patients undergoing infrarenal aortic operations found a decrease in hospital stay and risk of post-operative respiratory complications with early removal of NG tubes. ${ }^{26}$ Furthermore, a meta-analysis of 26 trials comparing selective versus routine NG decompression following elective laparotomy found significantly fewer pulmonary complications without NG decompression. ${ }^{27}$ Although distention and emesis were risks without routine decompression, this analysis found no significant differences in length of stay or complication rate. ${ }^{27}$ Traditionally, NG decompression has been used until return of bowel function in post-operative pancreas transplant recipients. However, a study from the University of Wisconsin comparing routine NG decompression versus discontinuation in SPK patients found that those without decompression had a shorter hospital stay without increased morbidity or decreased graft or patient survival. ${ }^{28}$ Early PO intake and early discontinuation of nasogastric decompression both may play a 
role in earlier return of bowel function, particularly in patients with a prior history of gastroparesis. In particular, a post-gastrectomy diet consisting of frequent smaller meals may be of benefit in patients with gastroparesis.

Chronic opioid use in patients with gastroparesis has been associated with increased inhospital mortality, length of stay, and increased cost of care based on a survey of the National Inpatient Sample database. ${ }^{29}$ Given the deleterious effects of chronic opioid use on bowel function and public health concern with chronic use, there has been an emphasis on alternative analgesia in surgical populations. Recent studies suggest that upwards of $6 \%$ of opioid naïve patients develop dependence following surgical procedures. ${ }^{30}$ Analysis of kidney transplant patients found that patients still filling opioid prescriptions 3 months post-transplant were even at higher risk of graft loss and mortality. ${ }^{31}$ In the post-operative pancreas transplant patient population narcotics certainly play a role in exacerbating symptoms and delayed return of bowel function. It is highly advisable to identify non-narcotic alternatives for post-operative analgesia. For example, the usage of transversus abdominis plane (TAP) anesthetic blocks can provide some post-operative pain relief and can be administered using on-Q pumps (C) (Avanos Medical, GA, USA) through catheters or as a single injection of liposomal bupivacaine. A comparison of pancreas transplant patients that underwent traditional opioid based post-operative analgesia versus TAP block with either continuous infusion bupivacaine or a single pre-operative injection of liposomal bupivacaine found lower opioid usage immediately post-operatively and quicker return of bowel function in patients who underwent either form of TAP block. ${ }^{32}$ Currently, we routinely perform TAP blocks on all recipients unless contraindicated. We prefer the single dosage of liposomal bupivacaine injections (10 ml or $133 \mathrm{mg}$ on each side) in the bilateral TAP spaces performed by the anesthesia team under ultrasound guidance. This is performed prior to incision because the planes are not yet distorted and in order to allow time for the anesthetic to work. This will typically provide several days of non-narcotic analgesia.

This article is protected by copyright. All rights reserved 
Other than local anesthetic blocks, there are few other good narcotic alternatives in this particular patient population. Unfortunately, the usage of non-steroidal anti-inflammatory agents which are typically used in ERAS protocols as an alternative to narcotics are typically prohibited with a fresh renal transplant due to well recognized nephrotoxicity given decreased renal perfusion via inhibition of prostaglandin associated afferent arteriole vasodilation. ${ }^{33}$ Finally, there is a group of medications which act as mu-opioid receptor antagonists with limited ability to cross the blood brain barrier that can help to alleviate some of the opioid-induced constipation and bowel motility issues in the post-operative patient without abolishing the opioid-induced analgesia and without causing withdrawal symptoms. Examples include Methylnaltrexone which is administered subcutaneously or a newer alternative Naloxegol which can be administered orally. Alvimopan is a similar acting medication which is more expensive and not as widely available due to a black box warning for increased incidence of myocardial infarction which was observed in a clinical trial of patients taking this medication long-term as a side-effect. ${ }^{34}$ Currently, only hospitals that have registered in and met all of the requirements for the Entereg Access Support and Education (E.A.S.E) program may use this drug. We routinely use methylnaltrexone $12 \mathrm{mg}$ subcutaneous injection per day for three days or until return of bowel function. Proton pump inhibitors are routinely prescribed and continued at least one month beyond the initial post-operative period, particularly in combination with steroids if used; and the patients are also permitted anti-nausea medications such as phenergan or ondansetron in the early post-operative period for nausea. By the third or fourth post-operative day, if the patient is still not passing stool, bisacodyl suppositories or enemas may be added. For lingering gastroparesis, nasojejunal tube feeds may be of great help in terms of providing nutrition as well as managing symptoms. The tube feeds, even at low volumes, stimulate the bowel which may improve some of the nausea symptoms and stenting of the pylorus with the nasojejunal tube may help facilitate gastric emptying. Certainly, if nasojejunal feeds are required for longer periods of time, placement of a percutaneous gastrojejunal feeding tube is reasonable.

\section{Pharmacologic Motility Agents}

This article is protected by copyright. All rights reserved 
Pharmacologic therapy has long been a mainstay of the treatment of diabetic gastroparesis, and there are a variety of agents that can be considered in the post-operative management of gastroparesis in the pancreas transplant population (Table 1). Metoclopramide has been used in the pharmacologic management of gastroparesis since the 1970s due to its antiemetic and prokinetic properties via blockade of dopamine D2 receptors. ${ }^{35}$ There have been five controlled trials and four open label series of metoclopramide demonstrating symptom improvement in 7 studies and accelerated gastric emptying in 5 studies. ${ }^{36-42}$ The most concerning side effects of metoclopramide use remain neurologic, particularly extra-pyramidal side effects, which are thought to be more prevalent with long-term use. ${ }^{35}$ Risk of tardive dyskinesia is higher in older adults, women and patients taking medicines for mental illness. Risk is also greater with long-term use, particularly longer than 12 weeks. As this is the most readily available and effective motility agent, we routinely include metoclopramide $10 \mathrm{mg}$ intravenous every 6 hours scheduled (unless contraindicated for allergy or prior side effects) as a component of the post-operative regimen. The metoclopramide is converted to oral administration prior to meals before the patient is discharged from the hospital and weaned as soon as possible in the outpatient clinic. Other than metoclopramide, there are few other ideal options for this patient population. Erythromycin, a macrolide antibiotic which functions as a motilin agonist stimulating gastric contraction and increasing gastrointestinal motility, is a good option for the general population of patients with diabetes and gastroparesis. Although trials in gastroparesis patients have reported symptom improvement, these have been limited by small sample sizes and limited follow-up. ${ }^{43}$ Unfortunately, erythromycin must be used with extreme caution in transplant patients due to its marked interaction with tacrolimus levels. ${ }^{44}$ Due to its ability to substantially increase tacrolimus levels, if used erythromycin should be ordered as a scheduled medication and taken with the same compliance as immunosuppression medications. Furthermore, on discontinuation, tacrolimus dosages should be adjusted and levels should be monitored closely. Erythromycin therapy can also be limited in long-term use due to associated tachyphylaxis.

Domperidone is another alternative and is a dopamine 2 antagonist. This medication is not available in the United State but can be used in the treatment of gastroparesis if obtained elsewhere. Controlled trials comparing domperidone to metoclopramide have shown similar effects in terms of 
symptom improvement and accelerated gastric emptying, but without the extended side effect profile of metoclopramide. ${ }^{41,45}$ Cisapride, a 5-HT4 receptor agonist, is another agent shown to improve gastric emptying in two randomized controlled trials; however, use has been associated with QT prolongation and ventricular arrythmias leading to withdrawal of this medication from several markets. ${ }^{46-48}$

In addition to motility agents, there are other classes of medications that may also provide symptomatic control of nausea and anorexia in this setting. Antiemetics are certainly useful in the relief of nausea and vomiting. The 5-HT3-receptor antagonists (ondansetron, granisetron) as well as antihistamines (promethazine, diphenhydramine) are commonly used in this setting. ${ }^{49}$ Antianxiety benzodiazepine agents such as lorazepam may also reduce nausea in some patients. Use of the neurokinin receptor-1 antagonist aprepitant can also be considered in those patients with severe nausea and vomiting refractory to the use of motility agents and traditional antiemetics. ${ }^{50}$ Mirtazapine is an antidepressant that has been shown to improve nausea and vomiting in patients with gastroparesis. ${ }^{51}$ Dronabinol, a synthetic cannabinoid has also been used to reduce nausea as well as an appetite stimulant in this patient population.

\section{Endoscopic Management}

Given the difficulty in management of chronic gastroparesis in patients with diabetes and the limited pharmacotherapeutic options available for this patient population, invasive treatment modalities have been developed primarily to address pyloric dysfunction. Certainly, in all cases of ongoing nausea and/or vomiting even in the absence of abdominal distention, bowel obstruction should be ruled out with a contrast study such as a contrast fluoroscopic study or CT scan. Beginning in the early 2000s, endoscopic intra-pyloric injection of botulinum toxin has been used for treatment of severe gastroparesis. Endoscopy can also be used to perform routine biopsies and rule out esophagitis or gastritis including from fungal or viral etiologies. Five open label studies comprising gastroparetic patients of varying etiologies have demonstrated symptom relief and improvements in 
gastric emptying time. ${ }^{52-56}$ However, the follow-up time in these trials was relatively short and longest duration of observed symptom reduction was 2 months. ${ }^{55}$ Two small volume case series in pancreas transplant patients have shown subjective improvement of gastroparesis symptoms with intra-pyloric botulinum toxin injection with duration of improvement lasting on average 29 weeks. ${ }^{57,58}$ Despite the promise of such reports, when compared to placebo in two randomized controlled trials, intra-pyloric botulinum toxin injection failed to show statistical efficacy. ${ }^{59}$ If successful in relieving symptoms, intra-pyloric botulinum toxin injection can be repeated every few months as nausea, vomiting, and fullness typically improve over the initial two to six months after pancreas transplantation. If injections are required more than two or three times, consideration should be given to gastric per-oral endoscopic pyloromyotomy (GPOEM), in which a submucosal endoscopic tunneling technique is used to cut the pyloric muscle, for a more sustained response. ${ }^{60} \mathrm{~A}$ recent small volume retrospective series has shown improvement of nausea and vomiting in a mixed population of gastroparesis patients lasting up to 18 months; however, this method has only been adapted in case series of pancreas transplant recipients with gastroparesis to date. ${ }^{61}$ There are a variety of more invasive surgical procedures that have been used to address gastric emptying, including laparoscopic pyloromyotomy, gastric stimulator placement, traditional gastric drainage procedures up to and including near total gastrectomy but with limited success; however, these procedures carry the weight of additional morbidity, frequently leading to multiple operations without resolving the underlying issues and have not been routinely adopted in post-transplant patients.

\section{Autonomic Neuropathy and Treatment of Orthostatic Hypotension}

Neuropathy, both somatic and autonomic, are known complications of diabetes mellitus. Autonomic neuropathy and dysfunction, in particular, is associated with increased mortality in T1DM patients in both the transplant population and those on exogenous insulin regimens. ${ }^{62,63}$ Given longstanding diabetes and progressive secondary complications, most pancreas transplant recipients will exhibit neuropathy by the time of their transplantation. Orthostatic hypotension is a

This article is protected by copyright. All rights reserved 
manifestation of autonomic dysfunction of the sympathetic efferent pathway in responding to and accommodating short term blood pressure changes. ${ }^{64}$ Although autonomic dysfunction related to diabetes has been shown to improve in patients post pancreas transplantation, orthostatic hypotension remains a significant challenge in the post-operative period. ${ }^{65}$ This is of particular concern in post-operative patients because hypotension in this setting may impact on perfusion of the transplanted organs and may result in falls and injuries. It has been demonstrated that neurogenic orthostatic hypotension is significantly more likely to occur after SPK than after transplantation of a kidney alone and that it is strongly associated with the more rapidly occurring glycemic control observed in the early post-transplant period. ${ }^{66}$ In fact, it has been suggested that orthostatic hypotension in this setting may be considered an iatrogenic complication of successful pancreas transplantation. Furthermore, post-transplant orthostatic hypotension may be even more pronounced in recipients of both a pancreas and a kidney given the precipitous loss of pre-transplant volume overload with a newly functioning kidney. Many patients come to transplant with compensated blood pressure in this volume overloaded state, frequently on multiple blood pressure medications. In this post-operative phase, it is important to not immediately resume all of the home blood pressure medications, especially long-acting anti-hypertensive medications, until the patient is demonstrably hypertensive after discontinuation of the high-volume intravenous fluids frequently administered after renal transplantation. In order to identify this problem early, it is particularly important to routinely check orthostatic blood pressure measurements (lying/sitting/standing) in the early post-operative period.

\section{Management}

There are a variety of medications useful when addressing neurogenic orthostatic hypotension in the post-transplant patient (Table 2). Midodrine has been shown to have moderate efficacy in the treatment of orthostatic hypotension given its alpha1 adrenoceptor agonist function and has been successfully utilized in a cohort of kidney pancreas transplant patients in prior studies. ${ }^{67,68}$ The downside of midodrine is its relatively short (2-4 hour) duration of action and side effects such as supine hypertension, paresthesia, and piloerection. ${ }^{69}$ It is advisable to have the 
patient administer their first morning dosage immediately on waking so that it has an opportunity to have some impact when they get out of bed and start their day. Fludrocortisone is another mainstay of post-transplant pharmacologic treatment of orthostatic hypotension, providing volume expansion and increasing alpha adrenoreceptor sensitivity. Fludrocortisone can cause supine hypertension like midodrine and may also cause hypokalemia recalling that it is a recognized treatment for hyperkalemia. ${ }^{69}$ Pyridostigmine (Mestinon) is a cholinesterase inhibitor that when compared with midodrine showed a decreased drop in standing diastolic pressure and less supine hypertension. Unfortunately, given its mechanism of action, pyridostigmine comes with a side effect profile including diaphoresis, loose stools, and fasciculations. Droxidopa (Northera) is a more recently approved norepinephrine precursor for the treatment of orthostatic hypotension. When compared to midodrine in a meta-analysis of randomized trials, droxidopa was less efficacious than midodrine at raising standing systolic blood pressure but did not cause supine hypertension. ${ }^{70}$ Droxidopa also had the added benefit of a longer (6-8 hour) duration of action in comparison to midodrine. Methylphenidate, a medication most commonly prescribed for attention deficit hyperactivity disorder, is a piperidine derivative that is structurally related to amphetamine. This medication has a hemodynamic profile similar to amphetamine, but with a much lower incidence of side effects and much more favorable safety profile. Usage has been described for Postural Orthostatic Tachycardia Syndrome with some data for orthostatic hypotension. This medication can occasionally be considered in the setting of orthostatic hypotension but usage is limited by its modest efficacy and potential for psychologic side effects.

In addition to pharmacologic management of orthostatic hypotension it is also critical to first and foremost optimize fluid status through oral or intravenous fluid administration (Figure 2). In fact, in some situations the ideal approach would include placement of a tunneled central line with home administration of perhaps 1-2 additional liters of intravenous fluid per day. It may also be helpful to modify behavior, particularly by avoiding standing abruptly and discontinuing any prior dietary salt restrictions which may have been observed for years in the face of renal insufficiency or even liberalization of salt intake or supplementation with the administration of sodium tablets. ${ }^{69}$ Furthermore, as many of the pharmacologic treatment strategies manage orthostatic hypotension

This article is protected by copyright. All rights reserved 
by tolerating supine hypertension, it may be advisable for the patient to sleep with the head of the bed (or the entire bed) raised to a 30-degree angle. Finally, thigh high compression stockings such as Jobst graded compression stockings may be helpful in decreasing the drop-in blood pressure on standing, but long-term compliance with these garments is difficult to achieve.

\section{Conclusion}

Given longstanding diabetes, pancreas transplantation patients will exhibit many of the secondary complications related to their disease at the time of transplant. Despite pancreas transplantation having the potential to halt or reverse the progression of diabetic complications with the establishment of normoglycemia, many patients will present with severe manifestations of secondary complications, particularly gastroparesis and autonomic neuropathy. These two complications have a propensity to complicate the immediate post-operative period adding to patient morbidity, readmission rates, and cost of care. Although multiple treatment modalities exist for these complications, current evidence does not lend itself to one highly effective therapeutic option for either of these conditions. Furthermore, trials of newer pharmacologic agents and invasive techniques are lacking in the transplant population. Ultimately, gastroparesis and orthostatic hypotension remain challenging post-operative conditions for which establishing institutional protocols and flow charts for therapy can be very helpful.

\section{References}

1. Gruessner AC, Gruessner RW. Long-term outcome after pancreas transplantation: a registry analysis. Curr Opin Organ Transplant. 2016;21(4):377-85.

This article is protected by copyright. All rights reserved 
2. American Diabetes Association. Economic costs of diabetes in the u. S. In 2017. Diabetes Care. 2018;41(5):917928.

3. Intensive Diabetes Treatment and Cardiovascular Outcomes in Type 1 Diabetes: The DCCT/EDIC Study 30-Year Follow-up. Diabetes Care. 2016;39(5):686-93.

4. Kelly WD, Lillehei RC, Merkel FK, Idezuki Y, Goetz FC. Allotransplantation of the pancreas and duodenum along with the kidney in diabetic nephropathy. Surgery. 1967;61(6):827-37.

5. Sutherland DE, Gillingham K, Moudry-munns K. Pancreas transplantation: report on United States results from United Network for Organ Sharing Registry with comparison to non-United States results from the International Registry. Clin Transpl. 1990;:29-39.

6. Robertson P, Davis C, Larsen J, Stratta R, Sutherland DE. Pancreas transplantation in type 1 diabetes. Diabetes Care. 2004;27 Suppl 1:S105.

7. Stratta RJ, Gruessner AC, Odorico JS, Fridell JA, Gruessner RWG. Pancreas transplantation: an alarming crisis in confidence. Am J Transplant. 2016;16(9):2556-2562.

8. Horowitz M, O'donovan D, Jones KL, Feinle C, Rayner CK, Samsom M. Gastric emptying in diabetes: clinical significance and treatment. Diabet Med. 2002;19(3):177-94.

9. Choung RS, Locke GR, Schleck CD, Zinsmeister AR, Melton LJ, Talley NJ. Risk of gastroparesis in subjects with type 1 and 2 diabetes in the general population. Am J Gastroenterol. 2012;107(1):82-8.

10. Grover M, Farrugia G, Lurken MS, et al. Cellular changes in diabetic and idiopathic gastroparesis. Gastroenterology. 2011;140(5):1575-85.e8.

11. Faussone-pellegrini MS, Grover M, Pasricha PJ, et al. Ultrastructural differences between diabetic and idiopathic gastroparesis. J Cell Mol Med. 2012;16(7):1573-81.

12. He CL, Soffer EE, Ferris CD, Walsh RM, Szurszewski JH, Farrugia G. Loss of interstitial cells of cajal and inhibitory innervation in insulin-dependent diabetes. Gastroenterology. 2001;121(2):427-34.

13. Mearin F, Camilleri M, Malagelada JR. Pyloric dysfunction in diabetics with recurrent nausea and vomiting. Gastroenterology. 1986;90(6):1919-25.

14. Brzana RJ, Koch KL, Bingaman S. Gastric myoelectrical activity in patients with gastric outlet obstruction and idiopathic gastroparesis. Am J Gastroenterol. 1998;93(10):1803-9.

15. Koch KL, Calles-escandón J. Diabetic gastroparesis. Gastroenterol Clin North Am. 2015;44(1):39-57.

16. Ko CW, Chang CS, Wu MJ, Chen GH. Transient impact of hemodialysis on gastric myoelectrical activity of uremic patients. Dig Dis Sci. 1998;43(6):1159-64.

17. Lin X, Mellow MH, Southmayd L, Pan J, Chen JD. Impaired gastric myoelectrical activity in patients with chronic renal failure. Dig Dis Sci. 1997;42(5):898-906.

This article is protected by copyright. All rights reserved 
18. Du YT, Rayner CK, Jones KL, Talley NJ, Horowitz M. Gastrointestinal symptoms in diabetes: prevalence, assessment, pathogenesis, and management. Diabetes Care. 2018;41(3):627-637.

19. Hathaway DK, Abell T, Cardoso S, Hartwig MS, El gebely S, Gaber AO. Improvement in autonomic and gastric function following pancreas-kidney versus kidney-alone transplantation and the correlation with quality of life. Transplantation. 1994;57(6):816-22.

20. Gaber AO, Oxley D, Karas J, et al. Changes in gastric emptying in recipients of successful combined pancreaskidney transplants. Dig Dis. 1991;9(6):437-43.

21. Hathaway D, Abell T, Cardoso S, et al. Improvement in autonomic function following pancreas-kidney versus kidney-alone transplantation. Transplant Proc. 1993;25(1 Pt 2):1306-8.

22. Cashion AK, Holmes SL, Hathaway DK, Gaber AO. Gastroparesis following kidney/pancreas transplant. Clin Transplant. 2004;18(3):306-11.

23. Marshall WA, Mangus RS, Powelson J, Fridell JA. Impact of Diabetic Gastroparesis on Outcomes After Pancreas Transplantation. ASC 2016 Abstracts.

24. Fridell JA, Mangus RS, Powelson JA, Mujtaba MA, Chen JM, Taber TE. Pancreas transplantation in the new millennium: the Indiana University experience. Clin Transpl. Published online 2011:145-156.

25. Lassen K, Soop M, Nygren J, et al. Consensus review of optimal perioperative care in colorectal surgery: Enhanced Recovery After Surgery (ERAS) Group recommendations. Arch Surg. 2009;144(10):961-9.

26. Gouëffic $Y$, Rozec B, Sonnard A, Patra P, Blanloeil Y. Evidence for early nasogastric tube removal after infrarenal aortic surgery: a randomized trial. J Vasc Surg. 2005;42(4):654-9.

27. Cheatham ML, Chapman WC, Key SP, Sawyers JL. A meta-analysis of selective versus routine nasogastric decompression after elective laparotomy. Ann Surg. 1995;221(5):469-76.

28. Barth RN, Becker YT, Odorico JS, Sollinger HW. Nasogastric decompression is not necessary after simultaneous pancreas-kidney transplantation. Ann Surg. 2008;247(2):350-6.

29. Siddiqui MT, Bilal M, Schorr-lesnick B, Lebovics E, Dworkin B. Opioid use disorder is associated with increased mortality and morbidity in patients with gastroparesis. Ann Gastroenterol. 2019;32(4):370-377.

30. Brummett CM, Waljee JF, Goesling J, et al. New Persistent Opioid Use After Minor and Major Surgical Procedures in US Adults. JAMA Surg. 2017;152(6):e170504.

31. Abbott KC, Fwu CW, Eggers PW, Eggers AW, Kline PP, Kimmel PL. Opioid Prescription, Morbidity, and Mortality in US Transplant Recipients. Transplantation. 2018;102(6):994-1004.

32. Yeap YL, Fridell JA, Wu D, et al. Comparison of methods of providing analgesia after pancreas transplant: IV opioid analgesia versus transversus abdominis plane block with liposomal bupivacaine or continuous catheter infusion. Clin Transplant. 2019;33(6):e13581.

This article is protected by copyright. All rights reserved 
33. Lucas GNC, Leitão ACC, Alencar RL, Xavier RMF, Daher EDF, Silva Junior GB da. Pathophysiological aspects of nephropathy caused by non-steroidal anti-inflammatory drugs. J Bras Nefrol. 2019;41(1):124-130.

34. Kraft M, Maclaren R, Du W, Owens G. Alvimopan (Entereg) for the management of postoperative ileus in patients undergoing bowel resection. $P$ T. 2010;35(1):44-49.

35. Haans JJ, Masclee AA. Review article: The diagnosis and management of gastroparesis. Aliment Pharmacol Ther. 2007;26 Suppl 2:37-46.

36. Perkel MS, Moore C, Hersh T, Davidson ED. Metoclopramide therapy in patients with delayed gastric emptying: a randomized, double-blind study. Dig Dis Sci. 1979;24(9):662-6.

37. Snape WJ, Battle WM, Schwartz SS, Braunstein SN, Goldstein HA, Alavi A. Metoclopramide to treat gastroparesis due to diabetes mellitus: a double-blind, controlled trial. Ann Intern Med. 1982;96(4):444-6.

38. Ricci DA, Saltzman MB, Meyer C, Callachan C, Mccallum RW. Effect of metoclopramide in diabetic gastroparesis. J Clin Gastroenterol. 1985;7(1):25-32.

39. Mccallum RW, Ricci DA, Rakatansky H, et al. A multicenter placebo-controlled clinical trial of oral metoclopramide in diabetic gastroparesis. Diabetes Care. 1983;6(5):463-7.

40. Schade RR, Dugas MC, Lhotsky DM, Gavaler JS, Van thiel DH. Effect of metoclopramide on gastric liquid emptying in patients with diabetic gastroparesis. Dig Dis Sci. 1985;30(1):10-5.

41. Erbas T, Varoglu E, Erbas B, Tastekin G, Akalin S. Comparison of metoclopramide and erythromycin in the treatment of diabetic gastroparesis. Diabetes Care. 1993;16(11):1511-4.

42. Dumitrascu DL, Weinbeck M. Domperidone versus metoclopramide in the treatment of diabetic gastroparesis. Am J Gastroenterol. 2000;95(1):316-7.

43. Maganti K, Onyemere K, Jones MP. Oral erythromycin and symptomatic relief of gastroparesis: a systematic review. Am J Gastroenterol. 2003;98(2):259-63.

44. Chiang LH, Wu TH, Tsai TC, Lee WC. Coadministration of Erythromycin to Increase Tacrolimus Concentrations in Liver Transplant Recipients. Transplant Proc. 2019;51(5):1439-1441.

45. Patterson D, Abell T, Rothstein R, Koch K, Barnett J. A double-blind multicenter comparison of domperidone and metoclopramide in the treatment of diabetic patients with symptoms of gastroparesis. Am J Gastroenterol. 1999;94(5):1230-4.

46. Lehmann R, Honegger RA, Feinle C, Fried M, Spinas GA, Schwizer W. Glucose control is not improved by accelerating gastric emptying in patients with type 1 diabetes mellitus and gastroparesis. A pilot study with cisapride as a model drug. Exp Clin Endocrinol Diabetes. 2003;111:255-61.

47. Braden B, Enghofer M, Schaub M, Usadel KH, Caspary WF, Lembcke B. Long-term cisapride treatment improves diabetic gastroparesis but not glycaemic control. Aliment Pharmacol Ther. 2002;16:1341-6.

This article is protected by copyright. All rights reserved 
48. Lewis K, Alqahtani Z, Mclntyre L, Almenawer S, Alshamsi F, Rhodes A, et al. The efficacy and safety of prokinetic agents in critically ill patients receiving enteral nutrition: A systematic review and meta-analysis of randomized trials. Crit Care. 2016;20:259.

49. Camilleri M, Parkman HP, Shafi MA, Abell TL, Gerson L, American College of Gastroenterology. Clinical guideline: management of gastroparesis. Am J Gastroenterol. 2013;108(1):18-37.

50. Myint AS, Rieders B, Tashkandi M, et al. Current and emerging therapeutic options for gastroparesis. Gastroenterol Hepatol (N Y). 2018;14(11):639-645.

51. Malamood M, Roberts A, Kataria R, Parkman HP, Schey R. Mirtazapine for symptom control in refractory gastroparesis. Drug Des Devel Ther. 2017;11:1035-1041.

52. Ezzeddine D, Jit R, Katz N, Gopalswamy N, Bhutani MS. Pyloric injection of botulinum toxin for treatment of diabetic gastroparesis. Gastrointest Endosc. 2002;55(7):920-3.

53. Miller LS, Szych GA, Kantor SB, et al. Treatment of idiopathic gastroparesis with injection of botulinum toxin into the pyloric sphincter muscle. Am J Gastroenterol. 2002;97(7):1653-60.

54. Lacy BE, Crowell MD, Schettler-duncan A, Mathis C, Pasricha PJ. The treatment of diabetic gastroparesis with botulinum toxin injection of the pylorus. Diabetes Care. 2004;27(10):2341-7.

55. Bromer MQ, Friedenberg F, Miller LS, Fisher RS, Swartz K, Parkman HP. Endoscopic pyloric injection of botulinum toxin A for the treatment of refractory gastroparesis. Gastrointest Endosc. 2005;61(7):833-9.

56. Arts J, Van gool S, Caenepeel P, Verbeke K, Janssens J, Tack J. Influence of intrapyloric botulinum toxin injection on gastric emptying and meal-related symptoms in gastroparesis patients. Aliment Pharmacol Ther. 2006;24(4):661-7.

57. Thomas MP, Wilson $\mathrm{CH}$, Nayar $\mathrm{M}$, et al. Endoscopic botulinum toxin injection for the treatment of diabetic gastropathy in pancreas and islet-cell transplant patients. Exp Clin Transplant. 2012;10(2):168-71.

58. Ben-youssef R, Baron PW, Franco E, Walter MH, Lewis T, Ojogho O. Intrapyloric injection of botulinum toxin a for the treatment of persistent gastroparesis following successful pancreas transplantation. Am J Transplant. $2006 ; 6(1): 214-8$.

59. Bai Y, Xu MJ, Yang X, et al. A systematic review on intrapyloric botulinum toxin injection for gastroparesis. Digestion. 2010;81(1):27-34.

60. Hibbard ML, Dunst CM, Swanström LL. Laparoscopic and endoscopic pyloroplasty for gastroparesis results in sustained symptom improvement. J Gastrointest Surg. 2011;15(9):1513-9.

61. Nagaraju S, Al-Haddad M, Powelson J, Fridell J. Gastric Per-Oral Endoscopic Pyloromyotomy (GPOEM) after pancreas transplant. 2019 International Pancreas and Islet Transplantation Association.

62. Navarro X, Kennedy WR, Loewenson RB, Sutherland DE. Influence of pancreas transplantation on cardiorespiratory reflexes, nerve conduction, and mortality in diabetes mellitus. Diabetes. 1990;39(7):802-6.

This article is protected by copyright. All rights reserved 
63. Hathaway DK, El-gebely S, Cardoso SS, Elmer DS, Gaber AO. Autonomic cardiac dysfunction in diabetic transplant recipients succumbing to sudden cardiac death. Transplantation. 1995;59(4):634-7.

64. Mathias CJ. Orthostatic hypotension: causes, mechanisms, and influencing factors. Neurology. 1995;45(4 Suppl 5):S6-11.

65. Kennedy WR, Navarro X, Goetz FC, Sutherland DE, Najarian JS. Effects of pancreatic transplantation on diabetic neuropathy. N Engl J Med. 1990;322(15):1031-7.

66. Kuten SA, Graviss EA, Nguyen DT, Gaber AO, Knight RJ. Neurogenic orthostatic hypotension: an iatrogenic complication of successful pancreas transplantation. . 2019 International Pancreas and Islet Transplantation Association.

67. Hurst GC, Somerville KT, Alloway RR, Gaber AO, Stratta RJ. Preliminary experience with midodrine in kidney/pancreas transplant patients with orthostatic hypotension. Clin Transplant. 2000;14(1):42-7.

68. Izcovich A, González malla C, Manzotti M, Catalano HN, Guyatt G. Midodrine for orthostatic hypotension and recurrent reflex syncope: A systematic review. Neurology. 2014;83(13):1170-7.

69. Ricci F, De caterina R, Fedorowski A. Orthostatic Hypotension: Epidemiology, Prognosis, and Treatment. J Am Coll Cardiol. 2015;66(7):848-860.

70. Chen JJ, Han Y, Tang J, Portillo I, Hauser RA, Dashtipour K. Standing and Supine Blood Pressure Outcomes Associated With Droxidopa and Midodrine in Patients With Neurogenic Orthostatic Hypotension: A Bayesian Meta-analysis and Mixed Treatment Comparison of Randomized Trials. Ann Pharmacother. 2018;52(12):11821194.

\section{Figures and Tables}


Fig 1. Pathway for management of gastroparesis in post-operative pancreas transplant patients. (IU University)

Table 1. Pharmacologic therapy for treatment of gastroparesis in post-operative pancreas transplant patients, including clinical trial data and side effects.

Fig 2. Pathway for management of orthostatic hypotension in post-operative pancreas transplant patients. (IU University)

Table 2. Pharmacologic therapy for treatment of orthostatic hypotension in post-operative pancreas transplant patients, including mechanism of action and side effects.

This article is protected by copyright. All rights reserved 


\section{Gastroparesis:}

\section{Preemptive Strategies:}

Early oral intake

Early removal of nasogastric tube

Narcotic minimization:

Peri-Operative pain control: TAP blocks

Methylnaltrexone (12 mg SQ QD POD 1-3)

Pharmacologic Therapy:

Metoclopramide (10 mg IV q6h)

Erythromycin (interacts with calcineurin inhibitors)

Domperidone/Cisapride (not available in USA)

Antiemetic medications

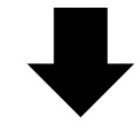

Interventions:

Intrapyloric botulinum injection

GPOEM (gastric per-oral endoscopic pyloromyotomy)

ctr_14270_f1.jpeg 


\section{Orthostatic Hypotension:}

\section{Preemptive Strategies:}

Optimize intravenous fluid resuscitation

Discontinuation of anti-hypertensives

Keep head of bed elevated

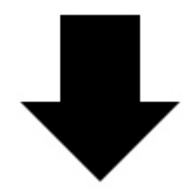

Pharmacologic therapy:

Midodrine (10 mg po q8h)

Fludrocortisone

Pyridostigmine

Droxidopa

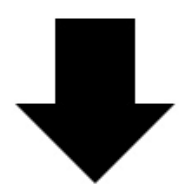

Tunneled central line and Home IV fluids

Liberalization of sodium / salt tablets

Jobst graded compression stockings

ctr_14270_f2.jpeg 